\title{
THE IMPLEMENTATION OF SUSTAINABILITY IN HIGHWAY PROJECTS
}

\author{
F. KEHAGIA \\ Department of Civil Engineering, Aristotle University of Thessaloniki, Thessaloniki, Greece.
}

\begin{abstract}
Today, the implementation of the notion of sustainability in highway construction is an imperative need since economic and social development simultaneously with the environmental protection is worldwide accepted. Well-planned highway projects add to the quality of life. The main question is how to provide innovative and high serviceability roads all by preserving the environment. In this paper, the practical and conceptual aspects of sustainable highway are presented. Additionally, it is pointed out how traditional highway construction process can be improved by incorporating the basic guidelines of sustainable development.
\end{abstract}

Keywords: construction, design, environment, highway, sustainable development.

\section{INTRODUCTION}

Road construction is a critical component of human activities. The development of economic activity would be difficult without extended road networks. The economic and social benefits of roads are numerous: enhance the economic growth, reduce travel time, reduce transportation cost, provide access to a variety of critical goods and services and offer new employment opportunities.

Several decades ago, the principal constraints affecting new highway projects were chiefly technical and economic. Engineers and contractors did not have to worry about how a highway would affect the environment. Now, threats against environment quality have led to an increasing awareness. A new construction in highway engineering causes serious negative short-and long-term effects on the environment such as noise disturbance, greenhouse gas emissions, habitat fragmentation, direct loss of habitat (flora and fauna), alteration of quality of adjacent habitat, local hydrological and erosion distress and unpleasant chemical effects.

The emerging discipline of sustainable development is a response to the growing aware that current levels and forms of economic activity threaten the planet's life support systems. The four dimensions that define and categorise the major principles of sustainability are technology, ecology, economics and ethics.

In the present paper, the practical and conceptual aspects of sustainable highway are presented.

The dimensions of sustainable development are not independent but instead intertwine in the trade-offs that are inherent in any engineering decision in general and the highway design in particular. Basic principles as the minimisation of use of non-renewable energy and natural resources, the minimisation of negative impact on the environment, the development of sustainable technologies, the economic valuation of the impacts of road projects and the trade-offs between the costs and benefits of different choices operate as available tools to implement sustainability on highway construction. The role of the highway engineer is to integrate science, technology, experience and innovation into highway construction in order to develop a more sustainable road project.

\section{THE MEANING OF SUSTAINABLE DEVELOPMENT}

It has been two decades since the term 'sustainable development' and 'sustainability' appeared following the 1987 publication of the United Nations World Commission on Environment and Development report, 'Our Common Future'. Sustainability has a time horizon that extends over 
human generations and focuses on conservation of natural resources while providing for basic social and economic conditions. Nevertheless, many definitions, often incompatible, have been proposed and debated based on different point of views. Sustainability has become a new watchword by which different aspects of the environmental challenges be addressed.

Deep analysis of the meaning of sustainability leads to some key conceptual issues:

1. Sustainability concerns about long-term risks of current resource consumption reflecting the goals of 'intergenerational equity'. The standard approach to intergenerational trade-offs in economics involves assigning benefits and costs according to some representative set of individual preferences and discounting costs and benefits accruing to future generations. What is required is some sort of intergeneration social contract. To satisfy this contract, the current generation might rule out in advance actions that could result in damage impacts beyond a certain threshold of cost and irreversibility [1].

2. The second key component of sustainability involves the specification of what is to be sustained. According to the Oxford English Dictionary (1989), the meaning of sustainable is 'capable of being maintained at a certain rate or level'. The New Oxford Dictionary of English (1998) defines sustainable as 'conserving an ecological balance by avoiding depletion of natural resources'. Two competing definitions of sustainability exist due to the different theoretical viewpoint. The first definition reflects the aspect of neoclassical economists who argue that utility should be sustained and future generations should be at least as well off as the present generations. Utility refers to average per capita utility of members of a generation. An efficient resource allocation is brought about the force of competition in competitive markets and the purpose of markets is to achieve efficiency. The environmental problems arise from market failure and the role of the economists is to define measures to correct those failures and allow markets to generate optimum state of the environment. Thus, if economic activity is not sustainable, then this is because markets are failing to make adequate provision for the failure [2-4]. The second definition reflects the aspect of ecological economics who argue that physical throughput should be sustained. The capacity of the ecosystem to sustain the biophysical resources and services is not to be run down and consumption should not deplete natural capital at a faster rate than it can be replaced by viable and durable human capital. Physical laws limit the extent to which other resources can be substituted for ecological degradation. Ecological economists attempt to account for non-market costs of economic activities determining the economic value of them which ignored in traditional economics [5]. They point out the difference between growth (increased quantity) and development (increased quality) and they focus on social welfare than material wealth measuring by gross domestic product. Although there is no general agreement regarding the precise meaning of sustainability, it is accepted that the development in order to increase people's standard of living (broadly defined) must be in such a way avoiding uncompensated future costs. The key principle is to integrate social, environmental and economic factors in decision making.

3. The third key component is the scale of human impact relative to global carrying capacity. Human welfare has to be improved by protecting the sources of raw materials used for human needs and ensuring that the sinks for human wastes are not exceeded.

\section{SUSTAINABLE HIGHWAYS}

Sustainable transport systems, in a general framework, are systems that adopt and put into practice fundamental guidelines of social, economical and environmental sustainability. They serve people's 
need for safe mobility as well as protecting the environment and support social equality, namely they are accessible to all people. In 1998, the Organization for Economic Cooperation and Development created the basic guidelines for the implementation of sustainable transport policies [6]. In 2001, one of the most important issues of the new White Paper 'European Transport Policy for 2010: time to decide' was sustainable transport systems based on alternative transport modes, transport multimodality, renewable energy sources, new technologies for improved energy consumption and safety [7].

Highway transportation is a central element in any transportation system. Nowadays, roads and vehicles are at the core of economy and society. An important concept in highway design is that every project is unique. The setting and character of the area, the values of the community, the needs and the opportunities of the highway users are unique factors that designers have to consider with each highway project. Sustainable highway is the highway that takes into consideration efficient mobility and safety issues while at the same time it addresses human and environmental aspects. The selection of routes, the design of the alignment and the location of intersections are based primarily in engineering considerations (highway standards) in order to achieve basic functional requirements as access, capacity, level of service, safety and travel time. These infrastructure-oriented methods have the objective to provide the highest quality service at the lower cost. The essence of sustainable highway is the combination of functional requirements while improving natural, built and social environments. In ecological economist terms, a highway project can be planned, designed, built and operated in such a way that when assessed on an overall basis, they present a net positive to the environment. Hal Kassoff said 'the goal of sustainable highways may at first sound like an oxymoron, but in reality represents an opportunity whose time has come' [8].

The basic criteria in order to a sustainable highway designed and constructed are as follows:

- Environmental stewardship: It is of paramount importance the cooperation and the co-ordinated multidisciplinary teamwork by engineers, landscape designers, planners, environmental scientists and ecologists. The active participation of professionals has a result of the holistic approach of the planning, design and construction of highway project and the setting of appropriate environmental management strategies.

- Best practices and policies: The environmental stewardship develops and implements practical and affordable ways to respect, conserve and enhance natural and social environment. The environmental policy which provides an action plan with clear objectives and targets should be compliant with relevant environmental legislation and regulations. Sound policies as context sensitive design, landscape management and lifecycle engineering practices when applied across all phases of highway construction can result in sustainable highway.

- Measurement and evaluation: The development of environmental performance indicators ensures the implementation of measures. Procedures and guidelines for monitoring are important parts of evaluating environmental performance.

\section{PLANNING AND DESIGN OF HIGHWAYS}

Environmental issues are an increasingly important part of the design and planning stage of highway with a focus on minimising or mitigating the impact of each new road link. The constraints affecting new projects were not only technical and economic but also perceived threats to the quality of the environment have led to an increasing awareness about a project to be in harmony with the environment.

The type of the natural landscape, the terrain or topographical features of the land determines where roads can go and therefore strongly affect road network structure and pattern. Several ecological impacts of road system occur at much greater levels than the proportion or road surface 
in the landscape $[9,10]$. The main concept in road design is the understanding and the integration of the road network in a broader landscape in order to implement the basic rules of sustainable development. According to this new philosophy, engineers and contractors of a new road project have to make sure that the economic, social and environmental needs, from the new project, can be met efficiently and in an integrated manner For new designed projects, landscape considerations are examined by the engineers with the help of specialists (environmental professionals and landscape architects) in order to determine the sites along the road, to highlight prevailing characteristics, identify the openings provided by the route and measure their impact on the existing landscape patterns. The decision of the altitude of the vertical alignment or the different cross sections as the integration of cuttings, embankments, viaducts or bridges will obviously not have the same effects on the landscape [11].

The presence of nature conservation area or protected area with rare species or habitats is a significant factor that has to be considered in the route selection. The great challenge is to find integrated solutions to road design and to find the route that produces the greatest benefit and the least impact. Such solutions may involve various combinations of avoidance and mitigation and compensation measures.

\section{CONSTRUCTION OF HIGHWAYS}

For the engineer and designer, the implementation of sustainability in their project is a new challenge. Sustainable construction is the set of processes by which a profitable industry delivers built assets which enhance the quality of life, provide and support desirable natural and social environments and maximise the efficient use of resources [12]. The development of a more sustainable approach to highway construction leads to examine the following key areas:

- Sustainable management of natural resources: The characteristic of highway engineering is the consumption and the utilisation of huge amount of aggregate and asphalt materials. Replacement of natural soils, aggregates and cements with industrial by-product materials is desirable. Applications of re-use and recycling techniques, such as utilisation waste materials and by-products, present noticeable advantages such as reduction of quantities of useless materials to be disposed, conservation of natural resources of materials, reduction of energy consumption and reduction of environmental pollution [13]. Recycling needs an integrated approach. Government and industry must work together to set research agendas and technical standards. Government must set policies for integrating recycling into the culture of the country. Industry must develop its own sales efforts, invest in recycling, organise themselves, understand the social problems and work to locate markets for their products. Each of these partners has their own sets of needs and criteria for measurement and evaluation. Sometimes this results in competing objectives. Shared terms, standards, tests and innovative technologies must be created. Channels of communication and broadcasting must be enhanced and established.

- New environment-friendly technologies: Technology plays a very important role in sustainable development because it is one of the most significant ways in which we interact with our environment. Sustainable technologies are practical solutions to achieve economic development and human satisfaction in harmony with the environment. These technologies serve to contribute, support or advance sustainable development by reducing risk, enhancing cost effectiveness, improving process efficiency and creating processes, products or services that are environmentally beneficial or benign while benefiting humans. Technological change can be achieved from the use of new machines or capital goods or from the development of new techniques and methods of production. This change does not normally happen without effort, it normally requires research and development creating incentives to use environmental policies. 
Highway construction has different stages incorporating the extraction of raw materials, production of materials, transportation of materials and construction of the project. For environmental viewpoint, the framework of this construction process causes four serious environmental problems: natural resources depletion, energy consumption, waste accumulation and environmental degradation (the choice of equipment, construction machinery or vehicles, or the way that is operated; the road construction may influence the amount of the atmospheric pollution, emissions or particulates, the level of noise or possible effects of vibration).

A new way of thinking must be adopted to redirect highway construction process towards sustainability. Figure 1 represents a closed cyclical system of the highway construction process. Four new processes have been added to the traditional process of construction: environmental technologies, natural resources management, waste management and minimisation of environmental impacts. Each one of them gives a response to a specific sustainable challenge.

'Environmental technologies' incorporate strategies and mechanisms that mitigate environmental impacts at the root, through the application of preservation, pollution prevention, avoidance, monitoring, assessment and control strategies and mechanisms. It is essential to apply the most practicable, economic and environmentally effective methods, processes, equipment and machinery for earthworks

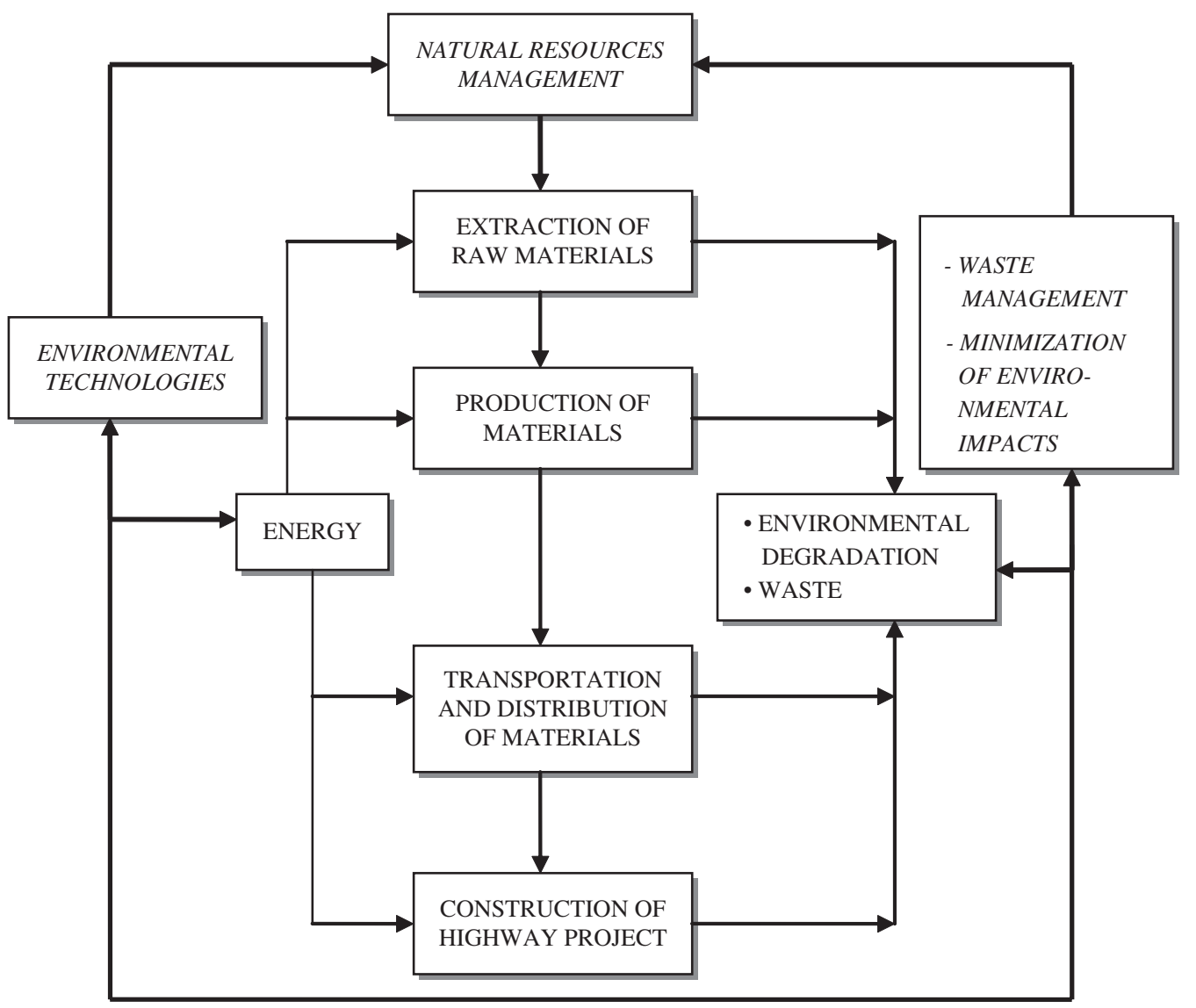

Figure 1: The framework of a sustainable highway construction process. 
consistent with optimal use of materials. Lifecycle analysis is a new strategy that meets the demand for sustainable engineering practice. It considers the impacts of a product from 'cradle to grave' and gives the opportunity to be assessed and compared to the total costs of different structural solutions, including all actions necessary over their entire service life [14].

'Natural resources management' addresses the need to ensure the most effective extraction and productive use of raw materials and achieve a high output/energy ratio by efficient use of machinery, fuel and electricity.

'Waste management' addresses the need to recover and recycle selected resources and products from waste. A wide range of alternative materials, industrial by-products or waste materials can be used in road construction as blast furnace slag, coal fly ash and recycled asphalt pavement. Applications of re-use and recycling techniques present noticeable advantages such as conservation of natural resources, reduction of quantities of useless materials to be disposed and reduction of energy consumption.

'Minimisation of environmental impacts' incorporates the design to implement the appropriate assessments, methods and processes to avoid or minimise the environmental impacts during the different stages of construction. It is important that the construction of a highway project is done with cost-effective methods to complete the work to specified engineering and environmental standards.

- Reducing emissions: Significant emissions arise from high construction activities. Air pollution, noise and dust can cause nuisance to local communities and reduce the suitability of adjacent areas for wildlife. Appropriate highway designs and practices have to be implemented in order to minimise the negative impacts in the environment. Moreover, appropriate measures have to be implemented to minimise the impact of construction on watercourses, water reserves, wetlands and rivers, groundwater or to reduce the risk of flooding. The awareness of road authorities and contractors about these issues should be increased.

- Mitigating habitat fragmentation: The construction of highway network inevitable leads to conflicts with other land uses such as nature conservation or agriculture. Moreover, another effect is the loss of habitat and the barrier effect to animal movements, both leading to the reduction of size of habitat patches. This may result in the isolation and extinction of vulnerable species. This fragmentation effect can be minimised in different ways (optimal alignment, chances in design, mitigation measures). When fragmentation is unavoidable and mitigation measures are ineffective, then compensation in the form of habitat creation may be appropriate measure [15].

- Landscape and heritage protection: It is vital important to respect the landscape character and quality of an area where the new highway will be constructed and integrate the road with the character of the surrounding landscape by maintaining the matrix of local vegetation pattern. The guidelines of landscape management will help to achieve the objectives.

\section{THE ECONOMIC DIMENSION OF SUSTAINABLE HIGHWAYS}

A traditional engineering approach to highway project is the project to be designed on economic grounds and criteria. There are many tools and techniques available to decision makers to provide the appropriate information in order to justify preferences and outcomes. Until now, the environmental impacts caused by highway project are predicted and measured in physical terms. The need for sustainable highway changes the meaning of the fundamental problem and imposes these negative, unpriced and non-market effects to be taken into account in the design and decision-making process.

For the economists the market-based valuations need not reflect the social importance of the services or the extent of the losses that we would suffer if these services were removed. The market-based 
F. Kehagia, Int. J. Sus. Dev. Plann. Vol. 4, No. 1 (2009)

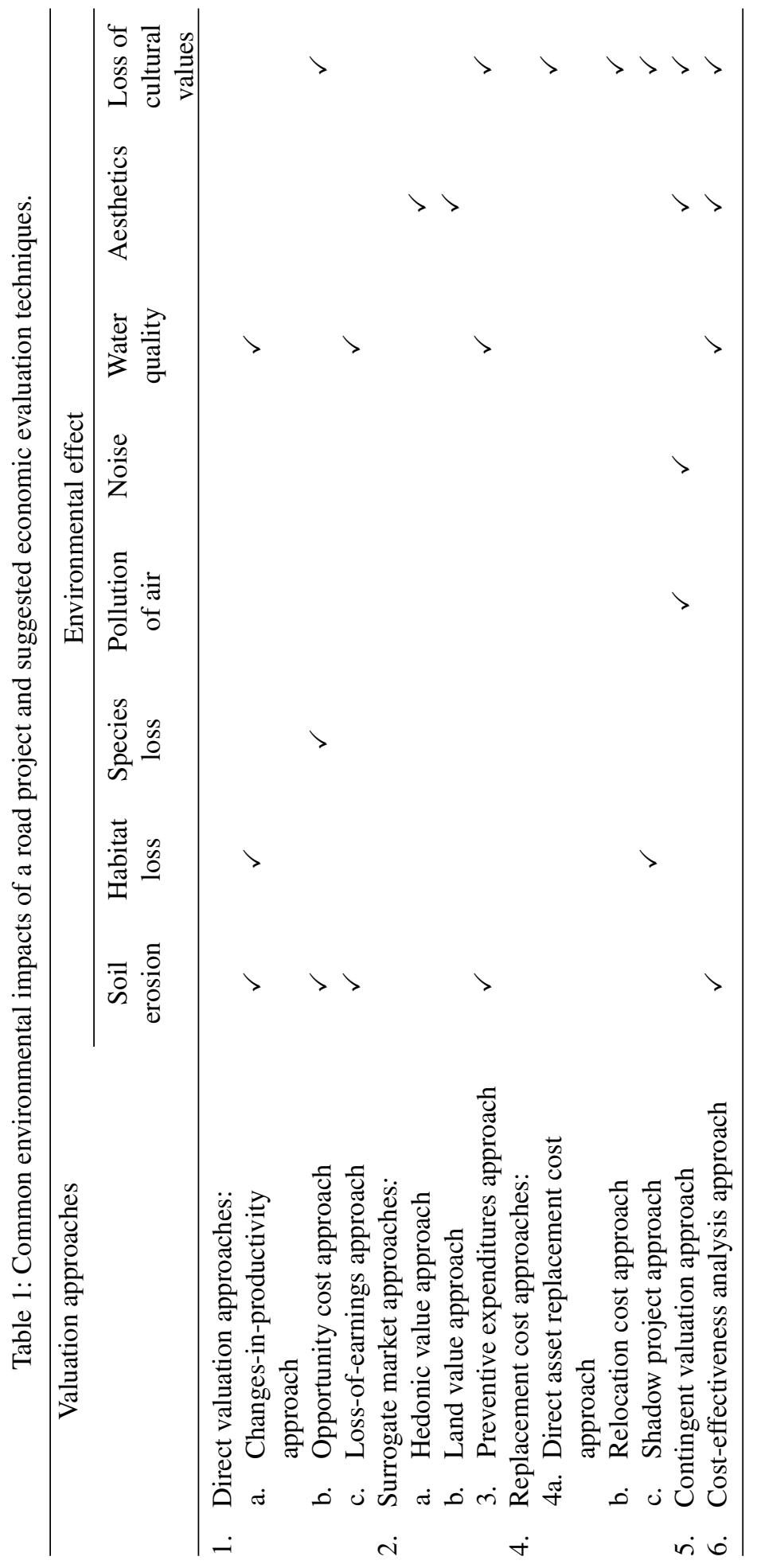


prices tell us the value to society of a small amount more or less of a service and do not indicate the overall contribution of the service. Methods and techniques are developed for valuing ecosystem services. The underlying concepts for these values are what a society would be willing and able to pay for a service (WTP) or what it would be willing to accept for a service loss (WTA) [16, 17]. The attempt to impose prices to the environmental impacts of highway projects has as result to treat environmental negative impact as a cost and environmental improvement as a gain within a conventional cost-benefit analysis. In Table 1, the economic valuation techniques are presented and are implemented to the most common environmental impacts of a highway project. The choice of the appropriate technique is depended by the characteristics of each technique, the impact to be valued and the available information.

\section{THE SOCIAL/ETHICS DIMENSION OF SUSTAINABLE HIGHWAYS}

The ethics of sustainability imply finding a balance between equity among humans in the present and equity between present and future generations. The principle of intergenerational equity and intragenerational equity is regarded as two of the fundamental pillars of the sustainable development. The role of sustainable highway is to provide and enhance the quality of human life but, at the same time, to protect the natural environment. Moreover, the impacts of highway infrastructure must be considered in a time frame marked by generations rather than just two or three decades.

The American Society of Civil Engineers (ASCE) recognises the leadership role of engineers in sustainable development and their responsibility to provide quality and innovation in addressing the challenges of sustainability. The ASCE Code of Ethics requires civil engineers to strive to comply with the principles of sustainable development in the performance of their professional duties. Kenneth Walsh [18], a professor of construction in Arizona State University, questioned if it is ethical for engineers to be responsible to the environment before the needs of a project construction. This is one of the difficult trade-offs required on an ethical basis in seeking to balance technological and environmental concerns that comprise sustainability. In environmental issues, the benefits and costs are often unclear, immeasurable or subject to debate.

The role of society is important to establish the basic principles, institutional arrangements and ethical standards on which a project would be constructed. These changes would occur as people begin thinking in terms of the effects of their own actions on the environment.

\section{CONCLUSIONS}

The combination of meeting accessible and effective mobility while improving the natural, built and social environment is the essence of sustainable highway. An effective highway project can be a catalyst for economic, social and regional development by integrating, social well-being, economic viability and environmental integrity.

Highway engineers have to promote and participate in multidisciplinary teams with other professionals, such as ecologists, economists and sociologists, to effectively address the issues and challenges of sustainable development. Road agencies have responsibilities to the local community beyond just the construction of highway. Best practice environmental management in road development and construction leads to achievement of the objective of sustainable highways.

\section{REFERENCES}

[1] Turner, R.K., Sustainable Environmental Economics and Management, Principles and Practices, Bellhaven Press: London, 1995.

[2] Pezzey, J., Economic analysis of sustainable growth and sustainable development. Environment Department Working Paper No. 15, World Bank, Washington DC, 1989. 
[3] Hartwick, J., Substitution among exhaustible resources and intergenerational equity. Review of Economic Studies, 45(2), pp. 347-54, 1978.

[4] Solow, R., On the intergenerational allocation of natural resources. Scandinavian Journal of Economics, 88(1), pp. 141-149, 1986.

[5] Daly, H., Sustainable Development: Definitions, Principles, Policies, World Bank, 2002.

[6] OECD, Guidelines towards Environmentally Sustainable Transport, 2003, www1.oecd.org/ publications/e-book/9702191E.PDF.

[7] Commission of the European Communities, European Transport Policy for 2010: Time to decide', White Paper, Brussels, 2001.

[8] Kassoff, H., Sustainable Highways: Oxymoron or Opportunity, Statement for House Subcommittee on Technology and Innovation, 2007.

[9] Forman, R., et al., Ecological effects of roads: toward three summary indices and an overview for North America. Int. Conf. on Habitat Fragmentation, Infrastructure and the Role of Ecological Engineering, Netherlands, 1995.

[10] Forman, R., Road Ecology, Science and Solutions, Island Press, 2003.

[11] Seiler, A., Ecological Effects of Roads: A Review, Department of Conservation Biology, Uppsala, 2001.

[12] Carpenter, T.G., Sustainable Civil Engineering, Vol. 2, England, 2001.

[13] Tilton, J., Exhaustible resources and sustainable development. Resources Policy, 22, pp. 91-97, 1996.

[14] Tielaitos, Life Cycle Assessment of Road Construction, Finnish National Road Administration, Helsinki, 1999.

[15] Trocmé, M., et. al., COST 341 - Habitat Fragmentation due to Transportation Infrastructure: The European Review, Office for Official Publications of the European Communities, 2003.

[16] Bowers, J., Sustainability and Environmental Economics. An Alternative Text, Addison Wesley Longman, 1997.

[17] Garrod, D. \& Wills, K., Economic Valuation of the Environment. Methods and Case Studies, Edward Elgar, 1999.

[18] Walsh, K., Do civil engineers have an ethical responsibility to their client at the expense of the environment? Civil Engineering, pp 62-63, December 1995. 